\title{
Phages of Listeria offer novel tools for diagnostics and biocontrol
}

\author{
Steven Hagens ${ }^{1}$ and Martin J. Loessner ${ }^{2}{ }^{*}$ \\ 'Micreos Food Safety, Wageningen, Netherlands \\ ${ }_{2}^{2}$ Institute of Food, Nutrition and Health, ETH Zürich, Zürich, Switzerland
}

\section{Edited by:}

Jennifer Mahony, University College

Cork, Ireland

Reviewed by:

Dahlene N. Fusco, Massachusetts

General Hospital, USA

Zeynep Atamer, Universität

Hohenheim, Germany

${ }^{*}$ Correspondence:

Martin J. Loessner, Institute of Food, Nutrition and Health, ETH Zürich,

Schmelzbergstrasse 7, CH-8092

Zürich, Switzerland

e-mail: martin.loessner@ethz.ch
Historically, bacteriophages infecting their hosts have perhaps been best known and even notorious for being a nuisance in dairy-fermentation processes. However, with the rapid progress in molecular microbiology and microbial ecology, a new dawn has risen for phages. This review will provide an overview on possible uses and applications of Listeria phages, including phage-typing, reporter phage for bacterial diagnostics, and use of phage as biocontrol agents for food safety. The use of phage-encoded enzymes such as endolysins for the detection and as antimicrobial agent will also be addressed. Desirable properties of candidate phages for biocontrol will be discussed. While emphasizing the enormous future potential for applications, we will also consider some of the intrinsic limitations dictated by both phage and bacterial ecology.

Keywords: bacteriophage, tools, diagnostics, typing, biocontrol, endolysins

\section{INTRODUCTION}

Bacteriophages affect the world in numerous ways. They represent parasites of bacteria, without own metabolism, relying on the host cell to provide energy and resources for their own replication. In terms of quantity, phages are the most abundant self-replicating entities on our planet, and outnumber their hosts by a factor of at least 10:1. This results in an estimated population of $10^{30}-10^{31}$ phage particles existing on the planet at any given time (Wommack and Colwell, 2000). In order to maintain this number, an estimated $10^{25}$ infections happen every second (Pedulla et al., 2003). In any environment where bacteria play an important role it therefore stands to reason that bacteriophage will have an impact on that environment. In the worlds' oceans and seas cyanobacteria play a vital role in primary production and most work focusing on ecological impact of phages has focused on their role in nutrient cycles. However, it should be obvious that, next to protozoa, phages are the only natural predators of bacteria and thus play an essential role in controlling bacterial populations everywhere. Bacteriophages also influence human lives in various other ways. Wherever bacteria are used in fermentation processes, be it for food or production of other compounds, phages can affect the end-result by infecting and lysing the desired bacteria. In the biological sciences, bacteriophages have been instrumental in building our understanding of fundamental genetic principles, such as the concept of the operon, functioning of promoters and the restriction-modification, one of the most valuable and versatile tools in molecular biology. Phages can contribute to the virulence of bacterial pathogens in two ways. General transduction is a process where instead of phage-DNA host-DNA is packaged into infectious phage-like particles and this host DNA is subsequently injected into a susceptible host where it may integrate into the chromosome through homologous recombination. Whenever this transduced DNA contains virulence genes the infected bacteria can have altered virulence. Although other strategies for survival and replication exist, most phages can be separated into temperate or virulent phages. The latter are often termed lytic or strictly lytic as well. This lifestyle involves obligate production of new phages after infection resulting in lysis of the host and release of progeny phage. Temperate phages can do this but alternatively they can integrate their genetic information into the host chromosome. Lysogenic conversion is the phenomenon where temperate phages alter the virulence of the infected host after DNA integration. Examples of bacteria that rely on phage (genes) for their full pathogenic potential are Vibrio cholera, which is only pathogenic when it the cholera toxin is introduced by phage CTX $\phi$, the diphtheria toxin of Corynebacterium diphteriae is also encoded by a phage, and shiga-toxin production in Enterobactericeae originates from genes on temperate phages integrated into the genomes of these bacteria (Freeman, 1951; Smith etal., 1983; Waldor and Mekalanos, 1996). Many more examples can be found in the literature. Lastly, phages have long been used in medical applications. Phage-typing has long been employed to conduct epidemiological studies of bacterial infection.

Over the past two decades, there has been a huge revival of interest in studying phages, but for other reasons. The emergence and increase in antibiotic-resistant bacteria and the possibility of replacing chemical drugs with phage or phage-encoded enzymes has been one of the main driving forces behind this renaissance. The fundamental insights which the genomics era has provided us with also led to the development of various tools based on phages or their components. Phage protein based detection of bacteria is now commercially available in the form of Vidas UP ${ }^{\circledast}$ technology, which employs recombinant host recognition proteins for in vitro diagnostics (IVD) of Escherichia coli and Salmonella. Phages have also been considered and applied since many decades to treat bacterial infections. This practice was and still is most common in the former Soviet Union, and to this day, phage preparations to treat a variety of infections are still produced in 
the Republic of Georgia. In the Western world, phage products for biocontrol are currently being commercialized for agricultural applications and food applications. Phage-derived proteins have also been commercialized and a number of commercial companies are investigating phage or phage-derived products for use in medical applications. The following chapters will focus on the impact of phage studies on our understanding of the genus Listeria with emphasis on Listeria monocytogenes as well as phage-derived tools for the detection and biocontrol of this important foodborne pathogen.

\section{THE GENUS Listeria}

Listeria spp. are small Gram-positive, flagellated rods with a ubiquitous distribution in the environment. Their principle lifestyle is saprophytic and thus the bacteria are frequently associated with plant material. Nine species are currently recognized, and they are L. monocytogens, L. ivanovii, L. innocua, L. marthii, L. rocourtiae, L. seeligeri, L. welshimeri L. fleischmannii, and L. grayii. Most research has been undertaken with respect to the human pathogen L. monocytogenes (Glaser et al., 2001; Graves et al., 2010; Leclercq et al., 2010; Bertsch et al., 2013). In healthy individuals, the infection (termed listeriosis) often manifests itself as a gastroenteritis, but in the very young, old, pregnant, and immunocompromised (a risk group commonly referred to as YOPIs), the bacteria can penetrate the intestinal tract and cause systemic infections including the central nervous system, and stillbirth or abortion in pregnant women (Vázquez-Boland et al., 2001). The disease is caused by the consumption of food contaminated with $L$. monocytogenes. The bacterium is a psychrotroph and can grow at refrigeration temperatures, and tolerates a wide range of $\mathrm{pH}$ and salt concentrations, rendering even low contaminations at production level dangerous if the shelf life of the food is longer than a few days (Gandhi and Chikindas, 2007). Many countries have strict regulations on the number of L. monocytogenes cells that are allowed in a given food, and zero-tolerance policies are in place in the US and Oceania. Phage therapy of Listeriosis is of course no option, as the bacteria multiply as intracellular pathogens, and cannot be reached by phages. Even antibiotics to which the bacteria are usually highly sensitive need to be administered at relatively high doses over prolonged periods of time in order to establish sufficient intracellular concentration. However, phage can be used both for the detection of this pathogen, and in controlling their presence in food processing equipment and on ready-to-eat products.

\section{BACTERIOPHAGES OF Listeria}

Listeria phages have been isolated from several of sources, including sewage plants, silage, food processing environments, and from lysogenic strains (Loessner and Busse, 1990; Hodgson, 2000; Kim etal., 2008; Arachchi et al., 2013). In total, some 500 phages specifically infecting Listeria have been identified, while only a limited number has been fully characterized on the molecular and genomic level (Loessner et al., 2000; Zimmer et al., 2003; Carlton et al., 2005; Dorscht et al., 2009; Schmuki et al., 2012). Phages have been reported to be able to infect other species. These studies revealed extensive mosaicism between many Listeria phages. All known Listeria phages belong to the order Caudovirales, which are tailed viruses with double stranded DNA. Podoviruses feature very short tails, while myoviruses have long, non-flexible contractile tail and siphoviruses have long, flexible tails. While members of both the Siphoviridae and Myoviridae are common, no Podoviridae infecting Listeria have yet been found and reported. The majority of the described phage are temperate, being able to integrate into the host genome. In fact, many Listeria strains are lysogenic, sometimes carrying multiple prophages, while most also harbor defective prophages. Many Listeria strains produce and release so-called monocins, which represent defective prophages, often recognized as lytic particles resembling phage tail structures (Zink et al., 1994, 1995). As in other bacteria, exposure to DNAdamaging agents such as UV light or Mitomycin C can induce the lytic cycle and lead to production of infective phage (Loessner, 1991). Listeria temperate phages generally display narrow host ranges, infecting only a small percentage of strains. This is in part caused by homoimmunity, i.e., resistance to a particular phage based on presence of a compatible repressor protein encoded by the same or a related phage within the bacterial cell. It is also noteworthy that the temperate phages of Listeria appear to be largely serovar-specific. It has been shown that this is based upon cell wall ligands, which the temperate phages recognize and attach to infect their hosts. They are serovar-specific sugar substituents of the polyribitol-phosphate teichoic acids on the Listeria cell wall (Wendlinger et al., 1996). In contrast, the large virulent phages such as A511 have been shown to use the cell-wall peptidoglycan backbone itself as a primary receptor (Wendlinger et al., 1996; Habann et al., 2014). Phages specifically infecting the different major serovar groups $(1 / 2,4,5$, and 6$)$ have been identified, while no phages for L. monocytogenes serovar 3 or L. grayii strains have yet been found. Very little data exist on phenotype conversion or alteration following lysogenization. A recent study shows that prophage integration into the Listeria comK gene hinders cells escaping from macrophage phagosomal environments. In this case, the prophage may be excised during intracellular growth without generating progeny phage, integrity of $\operatorname{comK}$ is reconstituted, and following a cascade of events triggered by the ComK protein, the bacteria can eventually escape (Rabinovich et al., 2012). Another study shows that cells which harbor a phage integrated into $\operatorname{comK}$ display enhanced persistence and higher cell densities under meat processing plant conditions compared to strains lacking the phages. However, no explanation is offered and the underlying mechanisms causing this phenomenon remain obscure (Verghese et al., 2011). The less frequent virulent phages of Listeria fall into three groups. The large $(\sim 140 \mathrm{~kb})$ Myoviruses P100 and A511 (Carlton et al., 2005; Klumpp et al., 2008) feature exceptionally broad host ranges, while the smaller siphoviruses P35 and P40 (around $40 \mathrm{~kb}$ ) and the recently described, slightly larger (70 kb) phage designated P70 (Dorscht et al., 2009; Schmuki et al., 2012) still infect most members of given serovar groups. Virulent phages, i.e., those that will always kill their host cells are of course most useful when phage-based biocontrol is the aim. In contrast, generalized transducing phages, even though they may feature a virulent lifestyle such as P35 (Hodgson, 2000), are not desirable for application in biocontrol because they may tranfer genetic material, including virulence factors from one strain to another (Hagens and Loessner, 2010). Preferred are members of 
a specific group of the large, virulent myoviruses closely related to P100 and A511, which have been isolated from sources in Europe, the US and New Zealand (Zink and Loessner, 1992; Carlton et al., 2005; Kim et al., 2008; Bigot et al., 2011; Arachchi et al., 2013).

The natural property of phage to specifically target and kill bacterial cells of a certain species or genus has been fairly well exploited with respect to Listeria. As mentioned above, phage therapy of L. monocytogenes infections is not possible. However, prevention of the disease by anti-Listeria control measures during and after food processing is highly effective and desirable. Phages used for biocontrol purposes should be virulent and feature a broad host range, i.e., infect and kill as many target strains as possible. They must also be unable to transduce, and should ideally be propagated on a non-pathogenic production strain, or alternatively needs to be purified from the bacterial lysate. As of now, two Listeria phage products are commercially available: a broad host range myovirus is marketed as "Listex ${ }^{\mathrm{TM}} \mathrm{P} 100$," and was granted GRAS (Generally Recognized As Safe) status by FDA and USDA in 2007 for use in all food products. Several studies have demonstrated its efficacy in foods such as cheese, RTE (ready to eat) meats and poultry, fruits, vegetables, and smoked fish, either alone or in combination with a growth limiting antimicrobial (Carlton et al., 2005; Soni and Nannapaneni, 2010a; Soni et al., 2010, 2012; Chibeu et al., 2013; Oliveira et al., 2014). Another study showed its efficacy on stainless steel surfaces, achieving more than five logs bacterial kill (Soni and Nannapaneni, 2010b). Another study used phage A511, closely related to P100, and confirmed its effectiveness in various RTE foods and surface ripenend soft cheeses (Guenther et al., 2009; Guenther and Loessner, 2011). Another product is termed "ListShield," and is also FDA and USDA approved. It consist of a cocktail of several phages, and its efficacy was investigated in two studies using fresh-cut produce in combination with the bacteriocin Nisin and as a spray application on honey-dew melons (Leverentz et al., 2003, 2004). An alternative approach to suspended phage is directed immobilization of the viral particles on cellulose membranes, which has been proposed as a possible intervention strategy against Listeria on packaging material (Anany et al., 2011).

\section{TOOLS BASED ON Listeria PHAGE}

Table 1 lists several Listeria phage-derived applications. The first widely used application was in phage typing. This is an inexpensive, low-tech and relatively quick tool to differentiate strains in epidemiological and microbial source-tracking studies. While being increasingly replaced by modern and more sophisticated molecular methods, it is yet not likely to become completely obsolete because of its simplicity and low cost. Phage typing had a prominent role in demonstrating food to be the primary cause of listeriosis in humans (Fleming et al., 1985). A number of different phage sets were developed (Audurier et al., 1979, 1984; Rocourt et al., 1985; McLauchlin et al., 1986; Loessner and Busse, 1990; Loessner, 1991; Estela and Sofos, 1993; Gerner-Smidt et al., 1993; van der Mee-Marquet et al., 1997). However, since Listeria serovar 3 strains appear resistant to phage infection, not all isolates can be typed. However, almost all strains that occur in foodborne outbreaks feature either serovar $1 / 2$ or $4 \mathrm{~b}$, and are mostly susceptible to phage infection and can therefore generally be differentiated using phage typing (van der Mee-Marquet et al., 1997). Transducing phages, while not suited for biocontrol purposes, have been used to transfer genetic traits from one strain to another, allowing genetic manipulation and phenotype investigations (Freitag, 2000; Hodgson, 2000). Lauer and coworkers provided specific E. coli/Listeria shuttle vectors designed to integrate into the Listeria chromosome after transformation. Here, site-specific integration by Listeria phage integrase has been employed to mediate single-copy, selection-free integration of genes placed on the vectors. As a proof of concept, the approach allowed successful complementation of actA and $h l y$ knockouts (Lauer et al., 2002). Derivatives of the initial pPL2 vector have

Table 1 | Listeria phage-derived tools.

\begin{tabular}{|c|c|c|}
\hline Phage or phage components & Application & Reference \\
\hline $\begin{array}{l}\text { Large sets of different phages (broad and } \\
\text { narrow host range) }\end{array}$ & Phage typing & $\begin{array}{l}\text { Audurier et al. (1979, 1984), Rocourt etal. (1985), McLauchlin } \\
\text { etal. (1986), Loessner and Busse (1990), Loessner (1991), } \\
\text { Estela and Sofos (1993), Gerner-Smidt et al. (1993), van der } \\
\text { Mee-Marquet et al. (1997) }\end{array}$ \\
\hline Single phages or cocktails (broad host range) & Biocontrol (targeted killing in foods) & $\begin{array}{l}\text { Leverentz et al. (2003, 2004), Carlton et al. (2005), Guenther and } \\
\text { Loessner (2011), Guenther et al. (2009), Soni et al. (2010, 2012), } \\
\text { Soni and Nannapaneni (2010a), Chibeu et al. (2013), Oliveira et al. } \\
\text { (2014) }\end{array}$ \\
\hline Reporter phages (broad host range) & Diagnostics (detection) & Loessner etal. (1996, 1997), Hagens et al. (2011) \\
\hline Phage endolysins and functional domains & Diagnostics & $\begin{array}{l}\text { Kretzer et al. (2007), Schmelcher et al. (2010), Walcher et al. } \\
\text { (2010), Tolba et al. (2012) }\end{array}$ \\
\hline Phage tail fibers & Immobilization and detection & Junillon etal. (2012), Habann etal. (2014) \\
\hline Endolysins and modified endolysins & Antimicrobial & Fischetti (2010), Schmelcher et al. (2012) \\
\hline Phage integrase genes & Site-specific integration vectors & Lauer etal. (2002) \\
\hline
\end{tabular}


since been used in many studies addressing L. monocytogenes phenotypes and virulence properties, have been successfully employed to monitor promoter activity in in vivo infection studies (Lenz and Portnoy, 2002; Lenz et al., 2003; Grundling et al., 2004; Bron etal., 2006), and were fundamental in elucidating the mechanisms of L-form formation in L. monocytogenes (Dell'Era et al., 2009).

Rapid and efficient detection of a Listeria contamination is critical with respect to food safety, and for compliance of food production with regulations concerning the presence of L. monocytogenes in foods and on food-contact surfaces. The high specificity of phages combined with the fact that viruses only multiply in viable and active host cells has sparked the development of phage amplification-based assays for the detection of various pathogens, including Listeria. One possible use is measuring an increase of Listeria phages after incubation with a contaminated sample (Bakulov et al., 1984). However, genetically modified reporter phages carrying a gene encoding an easy-to-measure product or activity offer more interesting and versatile alternatives. The reporter gene product will only be made following successful phage infection and gene expression. Listeria reporter phage A511::luxAB transduces a lux $A B$ gene fusion coding for bacterial luciferase (Loessner et al., 1996), and its efficacy in rapid detection of low-level Listeria contaminations from various foods has been demonstrated (Loessner et al., 1997). The same phage was used to construct A511::celB, featuring a thermophilic glycosidase of Pyrococcus furiosus. Reporter genes from thermophiles feature an exceptional ease-of-use, and allow a wide range of substrates and assay formats to choose from (Hagens et al., 2011).

Rather than employing complete phages as antimicrobials and for diagnostics, proteins and peptides from phage may also be used for this purpose. Phage-encoded cell-wall-hydrolyzing enzymes are particularly useful. In order to digest the bacterial cell wall prior to release of phage progeny, most phages produce a class of enzymes termed endolysins. These enzymes feature a two-domain structure with an $\mathrm{N}$-terminal catalytic domain and a C-terminal cell wall-binding domain (CBD) that binds with high affinity to cell wall-associated ligands, in order to direct the catalytic activity to its target site, and at the same time prevent collateral damage and lysis of yet uninfected potential host cells (Loessner et al., 1995). Such endolysin peptidoglycan hydrolases have a huge potential as antimicrobial reagents against Gram-positive pathogens, which has been reviewed elsewhere (Fischetti, 2010; Schmelcher et al., 2012). Yet, application of Listeria phage endolysins as highly specific antimicrobial agent in foods is hampered by the specific requirements of these enzymes, in terms of $\mathrm{pH}$ and salt concentration. Endolysins from Listeria phages can, however, be useful for removing Listeria occurring on food-contact surfaces and in biofilms.

Due to the high binding affinity and specificity of the endolysin CBD, these protein domains have been explored and used as versatile tools for diagnostics and identification of Listeria. Studies have shown that CBDs immobilized on paramagnetic beads are very effective in order to separate target cells from dilute suspensions, and the technique can be elegantly combined with different secondary diagnostic steps (Kretzer et al., 2007; Walcher et al., 2010). A recent study investigated detection of Listeria cells using electrochemical impedance spectroscopy (EIS), which can measure bacteria captured by the CBD molecules immobilized on a gold screen printed electrode (SPE; Tolba et al., 2012). Differently colored fluorescent proteins fused to CBDs with different recognition and binding spectra allow for rapid and multiplexed detection and differentiation of Listeria strains by fluorescence microscopy (Schmelcher et al., 2010). As an alternative approach, Listeria phage tail fiber proteins coupled to a solid support can also be used to bind target cells for primary enrichment and subsequent detection (Junillon et al., 2012).

In summary, the past years have demonstrated that phages infecting Listeria and other bacteria (Hagens and Loessner, 2010) provide us with numerous novel tools for various interesting approaches. The evolution of molecular microbiology and genetic engineering as technology platform, together with insights into phage biology, have been combined in interesting ways, and it is likely that this process will continue and more tools harnessing the properties and incredible biological specificity of bacterial viruses will be developed and available in the future.

\section{REFERENCES}

Anany, H., Chen, W., Pelton, R., and Griffiths, M. W. (2011). Biocontrol of Listeria monocytogenes and Escherichia coli O157:H7 in meat by using phages immobilized on modified cellulose membranes. Appl. Environ. Microbiol. 77, 6379-6387. doi: 10.1128/AEM.05493-11

Arachchi, G. J., Cruz, C. D., Dias-Wanigasekera, B. M., Mcintyre, L., Billington, C., Hudson, A., et al. (2013). Host range and in vitro lysis of Listeria monocytogenes seafood isolates by bacteriophages. Food Sci. Technol. Int. doi: 10.1177/1082013213497211 [Epub ahead of print].

Audurier, A., Chatelain, R., Chalons, F., and Piechaud, M. (1979). Bacteriophage typing of 823 "Listeria monocytogenes" strains isolated in France from 1958 to 1978 (author's transl). Ann. Microbiol. (Paris) 130B, 179-189.

Audurier, A., Taylor, A. G., Carbonnelle, B., and Mclauchlin, J. (1984). A phage typing system for Listeria monocytogenes and its use in epidemiological studies. Clin. Invest. Med. 7, 229-232.

Bakulov, I. A., Kotliarov, V. M., and Kol'pikova, T. I. (1984). Sensitivity of the phage titer increase test in detecting Listeria. Zh. Mikrobiol. Epidemiol. Immunobiol. 40-43.

Bertsch, D., Rau, J., Eugster, M. R., Haug, M. C., Lawson, P. A., Lacroix, C., et al. (2013). Listeria fleischmannii sp. nov., isolated from cheese. Int. J. Syst. Evol. Microbiol. 63, 526-532. doi: 10.1099/ijs.0.036947-0

Bron, P. A., Monk, I. R., Corr, S. C., Hill, C., and Gahan, C. G. (2006). Novel luciferase reporter system for in vitro and organ-specific monitoring of differential gene expression in Listeria monocytogenes. Appl. Environ. Microbiol. 72, 2876-2884. doi: 10.1128/AEM.72.4.2876-2884.2006

Bigot, B., Lee, W. J., Mcintyre, L., Wilson, T., Hudson, J. A., Billington, C., et al. (2011). Control of Listeria monocytogenes growth in a ready-to-eat poultry product using a bacteriophage. Food Microbiol. 28, 1448-1452. doi: 10.1016/j.fm.2011.07.001

Carlton, R. M., Noordman, W. H., Biswas, B., De Meester, E. D., and Loessner, M. J. (2005). Bacteriophage P100 for control of Listeria monocytogenes in foods: genome sequence, bioinformatic analyses, oral toxicity study, and application. Regul. Toxicol. Pharmacol. 43, 301-312. doi: 10.1016/j.yrtph.2005. 08.005

Chibeu, A., Agius, L., Gao, A., Sabour, P. M., Kropinski, A. M., and Balamurugan, S. (2013). Efficacy of bacteriophage LISTEXP100 combined with chemical antimicrobials in reducing Listeria monocytogenes in cooked turkey and roast beef. Int. J. Food Microbiol. 167, 208-214. doi: 10.1016/j.ijfoodmicro.2013. 08.018

Dell'Era, S., Buchrieser, C., Couve, E., Schnell, B., Briers, Y., Schuppler, M., et al. (2009). Listeria monocytogenes L-forms respond to cell wall deficiency by modifying gene expression and the mode of division. Mol. Microbiol. 73, 306-322. doi: 10.1111/j.1365-2958.2009.06774.x 
Dorscht, J., Klumpp, J., Bielmann, R., Schmelcher, M., Born, Y., Zimmer, M., etal. (2009). Comparative genome analysis of Listeria bacteriophages reveals extensive mosaicism, programmed translational frameshifting, and a novel prophage insertion site. J. Bacteriol. 191, 7206-7215. doi: 10.1128/JB. 01041-09

Estela, L. A., and Sofos, J. N. (1993). Comparison of conventional and reversed phage typing procedures for identification of Listeria spp. Appl. Environ. Microbiol. 59, 617-619.

Fischetti, V. A. (2010). Bacteriophage endolysins: a novel anti-infective to control Gram-positive pathogens. Int. J. Med. Microbiol. 300, 357-362. doi: 10.1016/j.ijmm.2010.04.002

Fleming, D. W., Cochi, S. L., MacDonald, K. L., Brondrum, J., Hayes, P. S., Plikaytis, B. D., et al. (1985). Pasteurized milk as a vehicle of infection in an outbreak of listeriosis. N. Engl. J. Med. 14, 404-407. doi: 10.1056/NEJM198502143 120704

Freeman, V. J. (1951). Studies on the virulence of bacteriophage-infected strains of Corynebacterium diphtheriae. J. Bacteriol. 61, 675-688.

Freitag, N. (2000). "Genetic tools for use with Listeria monocytogenes," in GramPositive Pathogens, ed. V. A. Fischetti (Washington, DC: ASM Press), 488-498.

Gandhi, M., and Chikindas, M. L. (2007). Listeria: a foodborne pathogen that knows how to survive. Int. J. Food Microbiol. 113, 1-15. doi: 10.1016/j.ijfoodmicro.2006.07.008

Gerner-Smidt, P., Rosdahl, V. T., and Frederiksen, W. (1993). A new Danish Listeria monocytogenes phage typing system. APMIS 101, 160-167. doi: 10.1111/j.16990463.1993.tb00096.x

Glaser, P., Frangeul, L., Buchrieser, C., Rusniok, C., Amend, A., Baquero, F., et al. (2001). Comparative genomics of Listeria species. Science 294, 849-852. doi: $10.1126 /$ science. 1063447

Graves, L. M., Helsel, L. O., Steigerwalt, A. G., Morey, R. E., Daneshvar, M. I., Roof, S. E., et al. (2010). Listeria marthii sp. nov., isolated from the natural environment, Finger Lakes National Forest. Int. J. Syst. Evol. Microbiol. 60, 1280-1288. doi: 10.1099/ijs.0.014118-0ijs.0.014118-0

Grundling, A., Burrack, L. S., Bouwer, H. G., and Higgins, D. E. (2004). Listeria monocytogenes regulates flagellar motility gene expression through $\mathrm{MogR}$, a transcriptional repressor required for virulence. Proc. Natl. Acad. Sci. U.S.A. 101 12318-12323. doi: 10.1073/pnas.0404924101

Guenther, S., Huwyler, D., Richard, S., and Loessner, M. J. (2009). Virulent bacteriophage for efficient biocontrol of Listeria monocytogenes in readyto-eat foods. Appl. Environ. Microbiol. 75, 93-100. doi: 10.1128/AEM.01 711-08

Guenther, S., and Loessner, M. J. (2011). Bacteriophage biocontrol of Listeria monocytogenes on soft ripened white mold and red-smear cheeses. Bacteriophage 1, 94-100. doi: 10.4161/bact.1.2.15662

Habann, M., Leiman, P. G., Vandersteegen, K., Van den Bossche, A., Lavigne, R., Shneider, M. M., et al. (2014). Listeria phage A511, a model for the contractile tail machineries of SPO1-related bacteriophages. Mol. Microbiol. 92, 84-99. doi: 10.1111/mmi.12539

Hagens, S., De Wouters, T., Vollenweider, P., and Loessner, M. J. (2011). Reporter bacteriophage A511::celB transduces a hyperthermostable glycosidase from Pyrococcus furiosus for rapid and simple detection of viable Listeria cells. Bacteriophage 1, 143-151. doi: 10.4161/bact.1.3.16710

Hagens, S., and Loessner, M. J. (2010). Bacteriophage for biocontrol of foodborne pathogens: calculations and considerations. Curr. Pharm. Biotechnol. 11, 58-68. doi: 10.2174/138920110790725429

Hodgson, D. A. (2000). Generalized transduction of serotype $1 / 2$ and serotype $4 \mathrm{~b}$ strains of Listeria monocytogenes. Mol. Microbiol. 35, 312-323. doi: 10.1046/j.1365-2958.2000.01643.x

Junillon, T., Vimont, A., Mosticone, D., Mallen, B., Baril, F., Rozand, C., et al. (2012). Simplified detection of food-borne pathogens: an in situ high affinity capture and staining concept. J. Microbiol. Methods 91, 501-505. doi: 10.1016/j.mimet.2012.09.015

Kim, J. W., Siletzky, R. M., and Kathariou, S. (2008). Host ranges of Listeria-specific bacteriophages from the turkey processing plant environment in the United States. Appl. Environ. Microbiol. 74, 6623-6630. doi: 10.1128/AEM.01282-08

Klumpp, J., Dorscht, J., Lurz, R., Bielmann, R., Wieland, M., Zimmer, M., et al. (2008). The terminally redundant, non-permuted genome of Listeria bacteriophage A511: a model for the SPO1-like myoviruses of gram-positive bacteria. J. Bacteriol. 190, 5753-5765. doi: 10.1128/JB.00461-08
Kretzer, J. W., Lehmann, R., Schmelcher, M., Banz, M., Kim, K. P., Korn, C., et al. (2007). Use of high-affinity cell wall-binding domains of bacteriophage endolysins for immobilization and separation of bacterial cells. Appl. Environ. Microbiol. 73, 1992-2000. doi: 10.1128/AEM.02402-06

Lauer, P., Chow, M. Y., Loessner, M. J., Portnoy, D. A., and Calendar, R. (2002). Construction, characterization, and use of two Listeria monocytogenes site-specific phage integration vectors. J. Bacteriol. 184, 4177-4186. doi: 10.1128/JB.184.15.4177-4186.2002

Leclercq, A., Clermont, D., Bizet, C., Grimont, P. A., Le Fleche-Mateos, A., Roche, S. M., et al. (2010). Listeria rocourtiae sp. nov. Int. J. Syst. Evol. Microbiol. 60, 2210-2214. doi: 10.1099/ijs.0.017376-0ijs.0.017376-0

Lenz, L. L., Mohammadi, S., Geissler, A., and Portnoy, D. A. (2003). SecA2-dependent secretion of autolytic enzymes promotes Listeria monocytogenes pathogenesis. Proc. Natl. Acad. Sci. U.S.A. 100, 12432-12437. doi: 10.1073/pnas. 2133653100

Lenz, L. L., and Portnoy, D. A. (2002). Identification of a second Listeria secA gene associated with protein secretion and the rough phenotype. Mol. Microbiol. 45, 1043-1056. doi: 10.1046/j.1365-2958.2002.03072.x

Leverentz, B., Conway, W. S., Camp, M. J., Janisiewicz, W. J., Abuladze, T., Yang, M., et al. (2003). Biocontrol of Listeria monocytogenes on fresh-cut produce by treatment with lytic bacteriophages and a bacteriocin. Appl. Environ. Microbiol. 69, 4519-4526. doi: 10.1128/AEM.69.8.4519-4526.2003

Leverentz, B., Conway, W. S., Janisiewicz, W., and Camp, M. J. (2004). Optimizing concentration and timing of a phage spray application to reduce Listeria monocytogenes on honeydew melon tissue. J. Food Prot. 67, 1682-1686.

Loessner, M. J. (1991). Improved procedure for bacteriophage typing of Listeria strains and evaluation of new phages. Appl. Environ. Microbiol. 57, 882-884.

Loessner, M. J., and Busse, M. (1990). Bacteriophage typing of Listeria species. Appl. Environ. Microbiol. 56, 1912-1918.

Loessner, M. J., Inman, R. B., Lauer, P., and Calendar, R. (2000). Complete nucleotide sequence, molecular analysis and genome structure of bacteriophage A118 of Listeria monocytogenes: implications for phage evolution. Mol. Microbiol. 35, 324-340. doi: 10.1046/j.1365-2958.2000.01720.x

Loessner, M. J., Rees, C. E., Stewart, G. S., and Scherer, S. (1996). Construction of luciferase reporter bacteriophage A511::luxAB for rapid and sensitive detection of viable Listeria cells. Appl. Environ. Microbiol. 62, 1133-1140.

Loessner, M. J., Rudolf, M., and Scherer, S. (1997). Evaluation of luciferase reporter bacteriophage $\mathrm{A} 511$ ::luxAB for detection of Listeria monocytogenes in contaminated foods. Appl. Environ. Microbiol. 63, 2961-2965.

Loessner, M. J., Wendlinger, G., and Scherer, S. (1995). Heterogeneous endolysins in Listeria monocytogenes bacteriophages: a new class of enzymes and evidence for conserved holin genes within the siphoviral lysis cassettes. Mol. Microbiol. 16, 1231-1241. doi: 10.1111/j.1365-2958.1995.tb02345.x

McLauchlin, J., Audurier, A., and Taylor, A. G. (1986). The evaluation of a phagetyping system for Listeria monocytogenes for use in epidemiological studies. J. Med. Microbiol. 22, 357-365. doi: 10.1099/00222615-22-4-357

Oliveira, M., Vinas, I., Colas, P., Anguera, M., Usall, J., and Abadias, M. (2014). Effectiveness of a bacteriophage in reducing Listeria monocytogenes on freshcut fruits and fruit juices. Food Microbiol. 38, 137-142. doi: 10.1016/j.fm.2013 08.018

Pedulla, M. L., Ford, M. E., Houtz, J. M., Karthikeyan, T., Wadsworth, C., Lewis, J. A., et al. (2003). Origins of highly mosaic mycobacteriophage genomes. Cell 113, 171-182. doi: 10.1016/S0092-8674(03)00233-2

Rabinovich, L., Sigal, N., Borovok, I., Nir-Paz, R., and Herskovits, A. A. (2012). Prophage excision activates Listeria competence genes that promote phagosomal escape and virulence. Cell 150, 792-802. doi: 10.1016/j.cell.2012. 06.036

Rocourt, J., Audurier, A., Courtieu, A. L., Durst, J., Ortel, S., Schrettenbrunner, A., et al. (1985). A multi-centre study on the phage typing of Listeria monocytogenes. Zentralbl. Bakteriol. Mikrobiol. Hyg. A 259, 489-497.

Schmelcher, M., Donovan, D. M., and Loessner, M. J. (2012). Bacteriophage endolysins as novel antimicrobials. Future Microbiol. 7, 1147-1171. doi: 10.2217/fmb.12.97

Schmelcher, M., Shabarova, T., Eugster, M. R., Eichenseher, F., Tchang, V. S., Banz, M., et al. (2010). Rapid multiplex detection and differentiation of Listeria cells by use of fluorescent phage endolysin cell wall binding domains. Appl. Environ. Microbiol. 76, 5745-5756. doi: 10.1128/AEM.00801-10 
Schmuki, M. M., Erne, D., Loessner, M. J., and Klumpp, J. (2012). Bacteriophage P70: unique morphology and unrelatedness to other Listeria bacteriophages. J. Virol. 86, 13099-13102. doi: 10.1128/JVI.02350-12JVI.02350-12

Smith, H. W., Green, P., and Parsell, Z. (1983). Vero cell toxins in Escherichia coli and related bacteria: transfer by phage and conjugation and toxic action in laboratory animals, chickens and pigs. J. Gen. Microbiol. 129, 3121-3137.

Soni, K. A., Desai, M., Oladunjoye, A., Skrobot, F., and Nannapaneni, R. (2012). Reduction of Listeria monocytogenes in queso fresco cheese by a combination of listericidal and listeriostatic GRAS antimicrobials. Int. J. Food Microbiol. 155, 82-88. doi: 10.1016/j.ijfoodmicro.2012.01.010

Soni, K. A., and Nannapaneni, R. (2010a). Bacteriophage significantly reduces Listeria monocytogenes on raw salmon fillet tissue. J. Food Prot. 73, 32-38.

Soni, K. A., and Nannapaneni, R. (2010b). Removal of Listeria monocytogenes biofilms with bacteriophage P100. J. Food Prot. 73, 1519-1524.

Soni, K. A., Nannapaneni, R., and Hagens, S. (2010). Reduction of Listeria monocytogenes on the surface of fresh channel catfish fillets by bacteriophage Listex P100. Foodborne Pathog. Dis. 7, 427-434. doi: 10.1089/fpd.2009.0432

Tolba, M., Ahmed, M. U., Tlili, C., Eichenseher, F., Loessner, M. J., and Zourob, M. (2012). A bacteriophage endolysin-based electrochemical impedance biosensor for the rapid detection of Listeria cells. Analyst 137, 5749-5756. doi: $10.1039 / \mathrm{c} 2 \mathrm{an} 35988 \mathrm{j}$

van der Mee-Marquet, N., Loessner, M., and Audurier, A. (1997). Evaluation of seven experimental phages for inclusion in the international phage set for the epidemiological typing of Listeria monocytogenes. Appl. Environ. Microbiol. 63, 3374-3377.

Vázquez-Boland, J. A., Kuhn, M., Berche, P., Chakraborty, T., Dominguez-Bernal, G., Goebel, W., et al. (2001). Listeria pathogenesis and molecular virulence determinants. Clin. Microbiol. Rev. 14, 584-640. doi: 10.1128/CMR.14.3.584-640.2001

Verghese, B., Lok, M., Wen, J., Alessandria, V., Chen, Y., Kathariou, S., et al. (2011). ComK prophage junction fragments as markers for Listeria monocytogenes genotypes unique to individual meat and poultry processing plants and a model for rapid niche-specific adaptation, biofilm formation, and persistence. Appl. Environ. Microbiol. 77, 3279-3292. doi: 10.1128/AEM.00546-11

Walcher, G., Stessl, B., Wagner, M., Eichenseher, F., Loessner, M. J., and Hein, I. (2010). Evaluation of paramagnetic beads coated with recombinant Listeria phage endolysin-derived cell-wall-binding domain proteins for separation of Listeria monocytogenes from raw milk in combination with culture-based and real-time polymerase chain reaction-based quantification. Foodborne Pathog. Dis. 7, 10191024. doi: 10.1089/fpd.2009.0475
Waldor, M. K., and Mekalanos, J. J. (1996). Lysogenic conversion by a filamentous phage encoding cholera toxin. Science 272, 1910-1914. doi: 10.1126/science.272.5270.1910

Wendlinger, G., Loessner, M. J., and Scherer, S. (1996). Bacteriophage receptors on Listeria monocytogenes cells are the $\mathrm{N}$-acetylglucosamine and rhamnose substituents of teichoic acids or the peptidoglycan itself. Microbiology 142(Pt 4), 985-992. doi: 10.1099/00221287-142-4-985

Wommack, K. E., and Colwell, R. R. (2000). Virioplankton: viruses in aquatic ecosystems. Microbiol. Mol. Biol. Rev. 64, 69-114. doi: 10.1128/MMBR.64.1.69114.2000

Zimmer, M., Sattelberger, E., Inman, R., Scherer, S., Calendar, R., and Loessner, M. J. (2003). Genome and proteome of Listeria monocytogenes bacteriophage PSA: an unusual case for programmed +1 translational frameshifting in structural protein synthesis. Mol. Microbiol. 50, 303-317. doi: 10.1046/j.1365-2958.2003.03684.x

Zink, R., and Loessner, M. J. (1992). Classification of virulent and temperate bacteriophages of Listeria spp. on the basis of morphology and protein analysis. Appl. Environ. Microbiol. 58, 296-302.

Zink, R., Loessner, M. J., Glas, I., and Scherer, S. (1994). Supplementary Listeriatyping with defective Listeria phage particles (monocins). Lett. Appl. Microbiol. 19, 99-101. doi: 10.1111/j.1472-765X.1994.tb00915.x

Zink, R., Loessner, M. J., and Scherer, S. (1995). Characterization of cryptic prophages (monocins) in Listeria and sequence analysis of a holin/endolysin gene. Microbiology 141(Pt 10), 2577-2584. doi: 10.1099/13500872-14110-2577

Conflict of Interest Statement: The authors declare that the research was conducted in the absence of any commercial or financial relationships that could be construed as a potential conflict of interest.

Received: 05 February 2014; accepted: 25 March 2014; published online: 10 April 2014. Citation: Hagens $S$ and Loessner MJ (2014) Phages of Listeria offer novel tools for diagnostics and biocontrol. Front. Microbiol. 5:159. doi: 10.3389/fmicb.2014.00159

This article was submitted to Virology, a section of the journal Frontiers in Microbiology. Copyright (c) 2014 Hagens and Loessner. This is an open-access article distributed under the terms of the Creative Commons Attribution License (CC BY). The use, distribution or reproduction in other forums is permitted, provided the original author(s) or licensor are credited and that the original publication in this journal is cited, in accordance with accepted academic practice. No use, distribution or reproduction is permitted which does not comply with these terms. 